\title{
The Economic Impact of COVID-19 on the Global Community
}

\author{
Andronova I.V. ${ }^{1,{ }^{*}}$ Digilina O.B. ${ }^{1}$ Andronov K.A. ${ }^{2}$ \\ ${ }^{1}$ Faculty of Economics RUND-University Moscow, Russia \\ ${ }^{2}$ Faculty of International Relations, MGIMO -University Moscow, Russia \\ *Corresponding author. Email: aiv1207@mail.ru
}

\begin{abstract}
The Covid-19 pandemic consequences remain to be estimated, as the world awaits a second wave. However, today we can sum up some preliminary results. The article presents the study of pandemic impact on the global economy as a whole and on the economies of the world's leading countries: the United States of America, China, Japan, Germany and Great Britain. It is noted that regardless Covid-19 spread rate, all five leading economies are affected. For example, the USA, according to preliminary data, lost $4.8 \%$ of GDP in the first three months of 2020, industrial production in March 2020 obtained its lowest level since 1946. As for the impact of Covid-19 on the global economy as a whole, the pandemic has shown once again the depth of the countries interdependence in the context of globalization. Despite the fact that the pandemic began in China, in terms of opened borders and free movement, it quickly gained global scale. Developing countries with underdeveloped health systems were found to be the most vulnerable. In conditions of a poorly established cases' registration and detection system, these countries may be the place of the virus continuing presence, which in the future may go beyond national borders and cause the second, third and so on waves. That is why international organizations, private foundations and states are working together both to develop a vaccine and to organize health care reforms in both developed and developing countries of the world. Time will show the successfulness of their efforts
\end{abstract}

Keywords: Covid-19, economic growth, pandemic, conflict of interest, globalization

\section{INTRODUCTION}

The Covid-19 pandemic is not only the worst global health crisis since the Spanish flu of 1918, but it is set to become one of the most economically costly pandemics in recent history. Experience gained from past epidemics provides some insight into the various potential costs that can arise in both the short and long term. At the same time, COVID19 differs from previous epidemics in several important ways. Since technology did not stand still, a lot has changed since 1918, many countries today are highly dependent on one another, which is why the damage caused to one country by the pandemic can affect the world economy as a whole and is reflected in the main macroeconomic indicators of countries as well as in stock, social and other indexes. For these reasons, this global crisis is unique.

\section{MATERIALS AND METHODS}

The purpose of this article is to determine the impact of the COVID - 19 pandemic on the economies of major developed countries and the global economy as a whole. To achieve this goal, we have analyzed documents published on the developed nations' government's official websites, the World Bank, and the World Health Organization materials, documents, and analytical reviews from the internet.

\section{DISCUSSIONS AND RESULTS}

Despite the fact that the first cases of COVID-19 date back to November 17. China notified the World Health Organization about a group of people infected with COVID-19 in the Chinese city of Wuhan on December 31, 2019.

From January 1 to 9 , the number of infected exceed 50 people. Due to the increase in cases, the authorities decided to close the Wuhan wet market, which was thought to be responsible for the spread of the virus. China reported the first COVID-19-related death shortly after.

The next period from January 10 to 20 is characterized by the spread of COVID-19 not only in China, but also in countries such as Thailand, Japan and South Korea. Following the second death from COVID-19, Japanese and Korean authorities started to examine the origin of the virus.

On January 23, WHO Director-General decided not to declare the COVID-19 outbreak a public health 
emergency. The number of infected raised up to 555 people and the number of deceased raised up to 17 people. Meanwhile, the virus spread to more and more countries. On January 25, new cases of infection were recorded in Australia, France (the first cases of infection in Europe), Malaysia and Canada. The total number of infected at the time rose to 2000 , and the death number has increased to 56 cases.

On January 27, Hong Kong was the first nation to impose an entry restriction on anyone who has visited Hubei province of China in the past 14 days. The number of infected approached 5000, the number of deaths has exceeded 100.

On January 30, WHO Director-General Tedros Adhanom Ghebreyesus finally declared the COVID-19 outbreak a public health emergency. The number of infected exceeded 9000 people, as of this date 213 deaths were recorded.

On January 30, after the emergency committee meeting, the virus was assigned the status of a pandemic, and the following message was issued: "WHO does not recommend and strongly insists against any restrictions on trade and transportation to China ... If any state decides to introduce such measures, it will be a mistake"[12].

On February 3, Hong Kong doctors took to the streets demanding the closure of borders with China. The World Bank released a statement saying they were mobilizing financial and technical resources to support countries affected by the COVID-19 outbreak. At the same time the first cases were recorded in Russia. The number of deaths was approaching 500, with the total number of infected exceeding 24,000.

On February 7, WHO reported shortages on the personal protection market. Demand has grown 100 times and prices increased dramatically, which, according to WHO, could "lead to depletion of reserves." . Meanwhile, the total number of infected exceeded 35 thousand people. The number of recorded deaths on this date was 700 .

On February 11 the Global Research and Innovation Forum undertook the trial to establish priority research areas on COVID-19. The death toll exceeded 1,000.

From February 13, China started imposing stiff restrictions on movement within its borders, which were supposed to last for about two weeks. At the same time, the number of cases was approaching 75 thousand people. On February 19 the number of deaths exceeded 2000 people.

In late February, the total number of people infected with COVID-19 had been growing, countries began applying more stringent measures to ensure the safety of their citizens, many states decided to close their borders with China.

In early March, the UN Central Emergency Response Fund provided 15 million dollars to the WHO and UNICEF in order to support the most defenseless countries, by monitoring the spread of COVID-19, investigating new cases, and helping national laboratories to operate. The World Bank also took part in the relief efforts, allocating 12 billion dollars to support national health agencies.
On March 11, the WHO Director-General officially declared the global COVID-19 outbreak a pandemic. Following the announcement, many large countries (UK, USA, some European countries, Russia) and various organizations began allocating sizable funds to support COVID-19 research and develop a vaccine.

By mid-March, 273 cases of COVID-19 infection were recorded in 26 African countries. European agencies started expressing concerns about African countries due to the poorly developed health systems and started preparing financial relief packages. On March 17, the World Bank announced its plan to provide additional 2 billion dollars to fight COVID-19.

On March 23, World Bank President David Malpass called on lenders to temporarily suspend pressure on the lowestincome and give them the opportunity to use their resources to combat COVID-19.On March 24, the number of infected exceeded 400 thousand people. It took almost 2 months for the number of infected to reach 100 thousand people, another 12 days for it to double and only 5 days for it to increase by another 200 thousand.

Meanwhile, the center of the epidemic shifted to the west. In the United States the number of infected grew from 30 at the beginning of March to almost 200 thousand people by the end of March. European countries were also among the most affected by the end of March: Italy (106 thousand people), Spain (100 thousand people) and Germany (71 thousand people). By late March, the total number of COVID-19 infections exceeded 850 thousand people, with more than 30 thousand deaths on record.

At the beginning of April, the virus continued to spread across the globe, forcing governments to impose strict measures to restrict the movement of citizens within their borders. The number of cases in African countries grew from 273 to almost 10,000 in mid-April. Russia became the next hotspot with the number of cases reaching 106 thousand by the late April. International organizations and states continued developing programs to support countries with poorly developed healthcare systems. On April 11, 2000 COVID-19-related deaths were recorded in the United States - the highest death rate so far. By the end of the month, the total number of infected hit 3.3 million. Countries most affected by the virus included: the United States (1 million cases), Spain (210 thousand cases), Italy (208 thousand cases), Great Britain (173 thousand cases of infection ), Russia (106 thousand cases). The total number of deaths exceeded 200 thousand people. Overall, more than 6 billion dollars were allocated to combat COVID-19 pandemic in April [2].

The continued to spread exponentially, crashing economy after economy in its wake.

To analyze the impact of the pandemic on economic processes, we selected five countries with the largest nominal GDP: the United States, China, Japan, Germany and the United Kingdom.

The US, the world's largest economy, lost an estimated $4.8 \%$ of GDP in the first three months of the year. On April 29, government data showed just how hard the economy was hit. US economic growth, as measured by gross domestic product, declined by $4.8 \%$ year-on-year in 
the first quarter of 2020 [1]. This is the sharpest decline since the 2008 global crisis, and it marks the end of the longest expansion in the country's history. This decline is partly due to the government implementing legislation in March restricting the movement of citizens. This immediately affected the demand, as businesses and educational institutions switched to operating remotely. Consumer spending, which accounts for two-thirds of the country's economic growth, showed the sharpest drop since 1980. Imports fell by $15.3 \%$, which is reflected in domestic demand decline. Exports fell by $8.7 \%$, as global demand declined due to COVID-19 containment measures, business investment fell by $8.6 \%$. As of April 18, about 26.6 million Americans had applied for unemployment benefits. The industrial sector of the economy also suffered from restrictive measures, similarly to the situation in March, industrial output fell to its lowest level since 1946 [4].

China-the world's second-largest economy lost about $6.8 \%$ GDP year-on-year in the first quarter of 2020, after continuously growing in the last three months of 2019. This is country's first decline in GDP since 2008 and it reflects the severity of the damage caused to the economy by the COVID-19 outbreak.

The authorities were forced to suspend almost all business activity in China for about 2 months, so losses in the industrial sector amounted to $9.6 \%$ and $5.2 \%$ in the service sector. Yet, the sharpest decline was recorded in the cars production (about 44.6\%). However, the Chinese officials argue, that the opportunity for long-term growth will not be affected by the short-term consequences of the COVID19 pandemic, since the country's economic fundamentals remain unchanged.

Among the major economic powers Japan is the country that was the least affected by COVID-19. With its crowded cities and aging population, why didn't COVID19 hit Japan harder? The data indicates a relatively low level of testing in Japan. Japan conducted 0.6 tests per thousand people, which is significantly less than developed countries. But while fewer tests have been performed, the number of deaths remained low and hospitals were not overcrowded with patients. Here are some facts that may give us an insight into Japan's success in fighting COVID-19. Although physical contact is common in the world, in Japanese culture physical contact (such as hugs, kisses, or handshakes) is usually avoided. In addition, special attention is paid to cleanliness and hygiene. In Japan, even before the outbreak, the use of face masks and hand sanitizer was incredibly widespread. Yet, despite the relatively low infection rate, economists forecast Japan's GDP to decline, as Japan needs foreign tourists spending to offset weak domestic consumption and to stimulate economic growth. Foreign workers also play a crucial role in addressing labor shortages, especially in agriculture, construction, and elderly care.

When it comes to German economy, there are 3 plausible scenarios: the baseline scenario and two risky scenarios. In the baseline scenario (the most likely scenario given the currently available data) GCEE assumes that the economic situation will return to normal over the summer, similar to the pattern emerging in China. In this case, GDP will fall by $2.8 \%$ in 2020 . In 2021 , the catch-up effect and the large transfer effect could lead up to $3.7 \%$ growth. According to the first risk scenario (the so - called scenario-V) - the economic consequences that may occur if production is stopped everywhere or if the restrictive measures take longer than was currently planned. In this case, the volume of production in the second quarter may be up to $10 \%$ lower than the current level. A sharper decline in the first half of 2020 will cause GDP to fall by $5.4 \%$ on average over the year [11]. If the measures to contain COVID-19 will continue beyond summer, the economic recovery will be substantially slowed. According to the second risk (the so - called-U scenario), the policy measures taken may not be sufficient to prevent serious damage to the economy as a result of bankruptcies and layoffs. Deteriorating financing conditions and increased uncertainty can also limit investment and lead to a reduction in household spending. Ultimately, in this scenario, there is a risk of negative feedback loops through the financial markets or banking system. In this scenario, the drop in 2020 is estimated to be $4.5 \%$. [7].

The UK is also facing a major recession due to the economic impact of the COVID-19 pandemic. The epidemic has affected the country's entire production capacity, combined with slowdown in global demand and concerns over the raw materials availability. As a result, country's machinery manufacturers temporarily stopped their production. For example, in March 2020, Joseph Cyril Bamford Excavators Ltd. (JCB) suspended production at all its UK plants due to declining demand for construction equipment. The company's global demand for products declined sharply as customers canceled orders and suspended deliveries. So the company stopped manufacturing in the UK to reschedule orders and inventory status, and focus on products that customers really need. Due to existing restrictions, the UK economy may fall by $35 \%$ in the second quarter of this year, the largest drop since 1956, and a budget deficit of $10-15 \%$ of GDP is also expected.

As a result, none of the top 5 countries remained untouched by the consequences of the COVID-19 pandemic. Thus, even Japan, which at the first stage of the analysis showed excellent economic indicators relative to other countries, showed its weaknesses and that the impact of the pandemic on the country is only a matter of time. [10]. China has experienced the peak of the epidemic and the process of economic recovery has begun, but the same cannot be said about the UK, Germany, the US and Japan, where the epidemic has not yet reached its peak, so we may see a deterioration in macroeconomic indicators in the future.

\section{CONCLUSION}

At the moment it is difficult to determine the scale of the impact of the COVID-19 epidemic on the economies of the biggest states, but a further drop in GDP as well as a reduction in trade and production in these countries are 
inevitable, which is going to cause painful consequences for the population. The pandemic shows that even the most developed countries are not prepared to deal effectively and quickly with the threat, and it has also helped to identify weaknesses in the health sector. The future recovery of the economies of the largest countries depends primarily on the coherence of actions of these countries and the world as a whole. It is important to maintain the openness and predictability of markets, and the creation of a favorable business environment for businesses is crucial for the resumption of investment. Further developments in the major economies also depends on the flash duration COVID-19, the severity of economic consequences for these countries are also directly correlated with the epidemic duration.

\section{REFERENCES}

[1] An official website of the United States government [Electronic resource] /. - Electron. text data. - Access mode: https: // whttps: //www.bea.gov/data/gdp/grossdomestic-product. free

[2] TradingEconomics [Electronic resource] /. Electron. text data. - Access mode: https://tradingeconomics.com/, free

[3] PWC UK [Electronic resource] /. - Electron. text data. - Access mode: https://www.pwc.co.uk/, free

[4] Macroeconomic effects of Covid-19: an early review [Electronic resource] / F. Boissay, P.

Rungcharoenkitkul. - Electron. text data. - 2020. Access mode: https://www.bis.org/publ/bisbull07.pdf, free

[5] COVID-19 Dashboard by the Center for Systems Science and Engineering at Johns Hopkins University [Electronic resource] /. - Electron. text data. - Access mode: https://coronavirus.jhu.edu/map.html07.pdf, free

[6] COVID-19 - a timeline of the coronavirus outbreak [Electronic resource] / J. Ravelo, S. Jerving. - Electron. text data. - 2020. - Access mode: https://www.devex.com/news/covid-19-a-timeline-ofthe-coronavirus-outbreak-96396, free

[7] German Economy Seen Shrinking 10\% This Quarter Due to Virus [Electronic resource] / Iain Rogers. -

Electron. text data. - 2020. - Access mode: https://www.bloomberg.com/news/articles/2020-0408/german-institutes-see-4-2-contraction-in-2020-thenbig-rebound, free

[8] Coronavirus impact felt across German economy [Electronic resource] /. - Electron. text data. - 2020. -
Access mode:

https://auto.economictimes.indiatimes.com/ news/industry/coronavirus-impact-felt-across-germaneconomy/74667843, free

[9] Gross Domestic Product, 1st Quarter 2020

[Electronic resource] /. - Electron. text data. - 2020. Access mode: https://www.bea.gov/data/gdp/grossdomestic-product, free

[10] Japan fumbles through the COVID-19 crisis [Electronic resource] / Chris Burgess, Tsuda University. - Electron. text data. - 2020. - Access mode: https://www.eastasiaforum.org/2020/04/17/japanfumbles-through-the-covid-19-crisis/, free

[11] Economic advisers: Coronavirus may see German GDP dip by over 5\% [Electronic resource] / Chris Burgess, Tsuda University. - Electron. text data. - 2020. - Access mode: https://www.dw.com/en/economicadvisers-coronavirus-may-see-german-gdp-dip-byover-5/a-52952713, free

[12] Recession sign: US economy shrinks 4.8 percent in first quarter [Electronic resource] / Patricia Sabga. Electron. text data. - 2020. - Access mode: https://www.aljazeera.com/ajimpact/recession-signeconomy-shrinks-48-percent-quarter200429120958454.html, free

[13] World health organization. Statements. URL: https://www.who.int/news-room/statements (date of access 9.04.2020) 